\title{
Using Proteomics to Understand Alzheimer's Disease Pathogenesis
}

\author{
Eleanor Drummond ${ }^{1} \bullet$ Thomas Wisniewski² \\ ${ }^{1}$ Brain and Mind Centre and Central Clinical School, Faculty of Medicine and Health, \\ University of Sydney, Sydney, Australia; ${ }^{2}$ New York University Alzheimer's Disease Center, \\ New York University School of Medicine, New York, NY, USA
}

Author for correspondence: Eleanor Drummond, Brain and Mind Centre and Central Clinical School, Faculty of Medicine and Health, University of Sydney, Sydney, Australia.

Email: eleanor.drummond@sydney.edu.au

Doi: http://dx.doi.org/10.15586/alzheimersdisease.2019.ch3

\begin{abstract}
Our current understanding of the molecular changes that drive Alzheimer's disease (AD) pathogenesis is incomplete. Unbiased, massspectrometry-based proteomic studies provide an efficient and comprehensive way to quantitatively examine thousands of proteins at once using microscopic amounts of human brain tissue. Recently, the number of proteomic studies that examine protein changes in AD brain tissue has been increasing. This chapter reviews the different proteomic approaches currently being used to identify pathological protein changes in $\mathrm{AD}$ brain tissue including bulk tissue studies that examine protein changes throughout the progression of $\mathrm{AD}$, studies of the insoluble proteome in $\mathrm{AD}$, studies using proteomics to examine selective vulnerability in $\mathrm{AD}$, studies of the amyloid plaque and neurofibrillary tangle proteome, studies of the synaptic proteome, and studies of the interactome of beta amyloid and tau. Combined, these complementary proteomic approaches provide increased understanding about the protein changes that occur in the AD brain. Results from these proteomic studies provide an excellent resource for future hypothesisdriven targeted studies and will help identify new biomarkers of disease and new drug targets for $\mathrm{AD}$.
\end{abstract}

In: Alzheimer's Disease. Thomas Wisniewski (Editor), Codon Publications, Brisbane, Australia. ISBN: 978-0-646-80968-7; Doi: http://dx.doi.org/10.15586/alzheimersdisease.2019

Copyright: The Authors.

License: This open access article is licensed under Creative Commons Attribution 4.0 International (CC BY 4.0). https://creativecommons.org/licenses/by-nc/4.0/ 
Keywords: Alzheimer's disease; interactome; mass spectrometry; neuropathology; proteomics

\section{INTRODUCTION}

Alzheimer's disease (AD) is a complex, multifactorial disease. Various genetic, environmental, and lifestyle risk factors have been associated with the development of $\mathrm{AD}$; however, none of these have been shown to definitively cause late onset $\mathrm{AD}(1)$. $\mathrm{AD}$ is diagnosed at autopsy by the presence of characteristic neuropathology: amyloid plaques and neurofibrillary tangles (NFTs), which primarily consist of aggregated beta amyloid $(A B)$ and hyperphosphorylated tau, respectively (2). The development of these neuropathological lesions is associated with increased neuroinflammation, synaptic loss, neurodegeneration, and ultimately the development of cognitive impairment that clinically characterizes $\mathrm{AD}$. Imaging and biomarker studies suggest that $\mathrm{AD}$ begins $\sim 20$ years before the development of dementia, resulting in a long preclinical stage of disease before clinical symptoms are apparent (3).

There are still significant gaps in our understanding about the molecular mechanisms that underlie the pathogenesis of AD. For example, we do not know what causes $\mathrm{AD}$, what factors drive the development of neuropathology, what factors cause the development of cognitive impairment, or what factors are responsible for the considerable heterogeneity in the rate of progression in people with AD. A greater understanding of all of these factors is essential for the development of effective therapeutics and discovery of new biomarkers for AD. New therapeutics are particularly needed for $A D$ as the previous record for $A D$ clinical trials has been very poor: $99.6 \%$ of AD clinical trials have failed, and currently, no disease-modifying treatment is available. This high failure rate has been attributed to various factors including starting treatment too late in the disease process, having the wrong drug targets, or relying too heavily on results from preclinical studies that use animal models of AD that poorly reflect human disease (4-6).

\section{THE BENEFITS OF USING PROTEOMICS TO STUDY PROTEIN CHANGES IN AD BRAIN TISSUE}

Traditionally, studies examining the molecular mechanisms that drive AD pathogenesis have used a targeted, hypothesis-driven approach that focuses on select proteins of interest. This approach has uncovered many of the major players involved in AD pathogenesis, most notably identifying beta amyloid $(\mathrm{A} \beta)$ as the major protein present in amyloid plaques $(7,8)$, identifying tau as the major protein present in NFTs (9), and identifying apolipoprotein E (apoE) as the most significant genetic risk factor for late onset $\mathrm{AD}(10,11)$. However, using a targeted approach precludes the discovery of novel disease-associated proteins and limits the ability to understand these protein changes in the broad context of AD. 
Unbiased, hypothesis-free "omics" studies such as genomic, transcriptomic, epigenetic and proteomic studies offer a comprehensive, highly efficient way to identify genes or proteins that are involved in the pathogenesis of AD. The highthroughput nature of "omics" studies means that they can be performed using microscopic amounts of human tissue samples, which are essential to study when examining diseases that are unique to humans, such as AD (12). Genomic and epigenetic studies have successfully identified new genetic risk factors for lateonset $\mathrm{AD}$ and have provided the basis for new hypothesis-driven studies examining how these genetic variants and epigenetic changes are involved in AD (13-16). Unbiased, mass-spectrometry-based proteomic studies of human AD brain tissue are essential to complement these genomic studies, particularly given that proteins are the druggable targets in AD. Furthermore, there is a poor correlation between RNA expression and protein levels in AD brain tissue; therefore, transcriptomic or genomic studies do not provide a complete picture of the pathogenic changes in the AD brain (17). Using mass-spectrometry-based proteomics to study the pathogenesis of AD has many advantages including the following: thousands of protein differences can be quantified simultaneously using microscopic amounts of brain tissue, the unbiased nature of these studies permits the discovery of novel proteins involved in AD pathogenesis, and proteomics can detect post-translational modifications on proteins (e.g. phosphorylation, oxidation, and ubiquitination) that are known to have an important pathological role in AD. The large amount of data generated in proteomic studies provides a comprehensive, bird's eye view of all protein differences that occur in AD, which can provide insight into the molecular mechanisms that cause AD at a network/ systems level, which is particularly useful when studying complex diseases like AD $(18,19)$. Mass-spectrometry-based proteomic studies have been limited in the past by technical and financial constraints; however, these factors have recently become less restrictive, and consequently, the number of proteomics studies using AD brain tissue has increased.

\section{AD PROTEOMIC STUDIES USING BULK TISSUE HOMOGENATES}

The majority of proteomic studies examining AD brain tissue have defined the proteomic changes between $\mathrm{AD}$ and age-matched, cognitively normal controls using bulk tissue samples. In these studies, proteomics is used to compare protein expression between AD and controls in brain homogenate, usually limited to one vulnerable brain region. Early liquid chromatography-mass spectrometry (LC-MS) studies generated preliminary findings about protein differences between AD and control brains, but were typically restricted by small sample sizes and therefore struggled to detect protein differences after correcting for multiple comparisons (20-26). More recent studies have included a larger number of samples, which are consequently sufficiently powered to detect hundreds of protein differences in AD brains $(17,27-34)$. Encouragingly, meta-analysis of these recent studies shows that many of the significantly altered proteins in AD brains are consistent, leading to increased confidence that these altered proteins are relevant to the pathogenesis of AD. 
The most comprehensive studies have been conducted by researchers at Emory University, USA $(17,30,31)$. Their studies primarily examined protein differences in the frontal cortex throughout the progression of $\mathrm{AD}$, specifically comparing protein levels in advanced $\mathrm{AD}$, asymptomatic $\mathrm{AD}$ (also referred to as preclinical AD), and age-matched cognitively normal subjects. Combined, these studies identified hundreds of protein differences present at different stages of AD. They found that the number of protein differences steadily increased with disease progression, suggesting that the number of protein differences is reflective of increased dysfunction involving more pathways as AD progresses. Their analysis allowed the identification of subsets of proteins that were exclusively altered in the symptomatic phase of $\mathrm{AD}$ and those that were altered prior to the onset of clinical symptoms. For example, they showed that proteins involved in synaptic function and synaptogenesis progressively decreased throughout AD, starting before clinical symptoms were present. They also showed that altered RNA metabolism and increased inflammation were present in AD brains in the earliest stages of disease prior to cognitive impairment. In contrast, astrocyte and microglia proteins increased in late stage $\mathrm{AD}$ and showed a strong correlation with the number of NFTs present. A consequent study by the same group specifically focused on the protein differences present in AD cases stratified by ApoE genotype (33). ApoE is the major genetic risk factor for late onset $\operatorname{AD}(35,36)$. The three alleles of ApoE (apoE2, apoE3, and apoE4) confer different risk for $\mathrm{AD}$ : apoE4 increases risk for $\mathrm{AD}$ and apoE2 decreases risk for $\mathrm{AD}$. Their proteomic results suggested that apoE may confer risk in AD through a combination of effects on inflammation, metabolism, and cerebral vasculature, and using their proteomic approach, they were able to pinpoint the specific proteins involved (33).

One important factor to be mindful of when interpreting and comparing proteomic studies is the type of tissue lysis method used prior to mass spectrometry. Different lysis methods enrich for different populations of proteins or even different pools of the same protein. For example, soluble and insoluble forms of the same protein may require different lysis methods for detection. Therefore, the use of various lysis methods can complicate meta-analysis of multiple proteomic studies as the same proteins are not always detected by each lysis method. However, one advantage of using varied lysis methods is that combined analysis of proteomic studies that use various lysis methods provides a richer view of molecular changes in the AD brain. For example, some studies have specifically examined differences in the insoluble proteome in $\mathrm{AD}(21,25,30,37)$, which enriches for proteins that are associated with the insoluble plaques or NFTs in AD, as well as other proteins that are independently prone to insolubility in the AD brain. Of these studies, Hales et al. provide the most comprehensive analysis of insoluble protein changes in $\mathrm{AD}$ (30). Interestingly, they showed that the number of differentially expressed proteins in the insoluble fraction increased with disease severity and that many of these insoluble proteins were involved in mitochondrial function, which is known to be decreased in $\mathrm{AD}$ (30). Other recent studies have used proteomics to answer specific questions about which proteins are primarily affected by post-translational modifications in AD. Two recent studies have used enrichment strategies to identify all proteins that are phosphorylated and ubiquitinated in $\mathrm{AD}(38,39)$. These studies showed that the number of ubiquitinated proteins was much higher in AD brains than in control brains, which is consistent 
with the accumulation of insoluble and misfolded proteins during AD and reflects the proteolytic stress present in $\mathrm{AD}$ (38). Examination of phosphorylated proteins confirmed that tau was the most highly phosphorylated protein in AD in comparison to controls and also identified an additional 142 proteins that were phosphorylated to a greater extent in AD brains (39).

\section{THE USE OF PROTEOMICS TO UNDERSTAND SELECTIVE VULNERABILITY IN AD}

One of the most striking features of $\mathrm{AD}$ is that specific brain regions are particularly vulnerable to the development of amyloid plaques, NFTs, and neurodegeneration, while other regions are comparatively resistant to pathology. Why this occurs is still unknown. However, various factors have been proposed to contribute to vulnerability including: gene expression, long axonal projections or large neuronal size, being an excitatory neuron, containing low levels of calcium buffering proteins, or containing high levels of metastable subproteome proteins that are prone to aggregate in times of stress (40-42). Defining a particular brain region as vulnerable or resistant in $\mathrm{AD}$ can be complex, as it depends on the neuropathological factor you use to define vulnerability. This is important because some brain regions are preferentially vulnerable to developing amyloid plaques, while others are preferentially vulnerable to developing NFTs or neurodegeneration, and the presence of these different types of neuropathology does not always correlate. In general, regions that are particularly vulnerable to the development of $\mathrm{AD}$ include the hippocampus, entorhinal cortex, basal forebrain, and locus coeruleus. Comparatively resistant regions include the cerebellum and occipital cortex.

Transcriptomics studies suggest that there is likely a distinct protein signature of vulnerable neurons in $\mathrm{AD}$ (43); however, this has not yet been comprehensively examined at the protein level. Proteomic studies of selective vulnerability in AD are complex as additional variables need to be considered in their experimental design. For example, basal protein differences between different brain regions have to be accounted for when interpreting protein differences that appear to be associated with increased vulnerability to $\mathrm{AD}$. This is particularly important when comparing brain regions that are morphologically different such as the cerebellum and the hippocampus. Disparate basal protein expression between brain regions complicates interpretation of results as protein differences could be due to either basal brain region differences or AD associated differences. Accounting for these variables is possible, but ultimately results in large, complex studies that require a large number of samples to perform all analyses with sufficient power.

The majority of bulk tissue proteomic studies have only analyzed one or two brain regions, usually focusing only on vulnerable brain regions, meaning that they cannot be used to examine the protein changes associated with selective vulnerability in $\mathrm{AD}$. Two recent studies have aimed to fill this knowledge gap. $\mathrm{Xu}$ et al. (44) performed the most extensive analysis of proteomic changes in the $\mathrm{AD}$ brain that are associated with selective vulnerability. They compared protein expression in three highly affected regions (hippocampus, entorhinal cortex, and 
cingulate gyrus), two lightly affected regions (sensory cortex and motor cortex), and one comparatively unaffected region (cerebellum). As expected, the majority of protein differences between AD and control brains were observed in the highly affected regions, and these protein changes were reflective of increased innate and adaptive immune responses in the brain and increased apoptosis. The fewer protein differences in the lightly affected regions appeared to be reflective of early stage pathology, suggesting that the same molecular changes that drive pathogenesis of AD eventually spread to these lightly affected regions. Intriguingly, the cerebellum actually showed a large number of protein differences between AD and controls, even more so than the lightly affected regions. However, these protein differences appeared to be reflective of potentially protective molecular changes such as increased expression of proteins associated with growth factors, increased oxidative defense proteins, and decreased transfer RNA synthetases. Mendonca et al. (45) also performed a comprehensive study looking at the proteomic differences in brain regions preferentially vulnerable to tau pathology in $\mathrm{AD}$. They compared the proteome in $\mathrm{AD}$ and controls in two brain regions that are highly vulnerable to the development of NFTs (parahippocampal cortex and entorhinal cortex) and two brain regions that are moderately vulnerable to the development of NFTs (temporal cortex and frontal cortex). In doing so, they generated a complex dataset that will be useful for future data mining studies examining the protein changes associated with tau pathology in $\mathrm{AD}$. In the future, expanding these studies to include comparisons between multiple brain regions at multiple stages of $\mathrm{AD}$ will be useful for defining the protein differences that underlie selective vulnerability in $\mathrm{AD}$ and to definitively determine whether mildly affected regions show molecular changes that are similar to those in early stage $\mathrm{AD}$.

\section{PROTEOMICS OF NEUROPATHOLOGICAL FEATURES PRESENT IN AD}

Other groups, including my own, have recognized the importance of performing localized proteomic studies that specifically focus on disease-associated neuropathological features or specific cell populations. Using a localized approach that focuses specifically on areas highly affected by disease has the potential to reveal protein differences between $\mathrm{AD}$ and controls that are particularly relevant to pathogenesis. We have focused our efforts on using a localized proteomics approach to determine the proteome of amyloid plaques, NFTs, and vulnerable neurons. In this approach, neuropathological features or vulnerable neuron populations are microdissected from sections of human brain tissue, and their protein composition is analyzed using mass spectrometry (46-48). A key advantage of our approach is that it can be performed using formalin-fixed paraffin-embedded (FFPE) tissue. This is important because the majority of human tissue specimens available for research are FFPE blocks of tissue that are collected and used during autopsy. Therefore, developing a method that is compatible with FFPE tissue greatly increases the feasibility of human tissue studies, particularly those using rare or unique cases. A second key advantage of our method is that it can be performed using microscopic amounts of tissue. We have successfully performed 
proteomics using as little as $1.5 \mathrm{~mm}^{2}$ of tissue, which is the equivalent of approximately 550 amyloid plaques or 4000 NFTs. This number of plaques and tangles can typically be collected using $<4$ tissue sections, showing just how little tissue is required for these studies. But the most important aspect of our approach is that we can quantify over a 1000 proteins at once using these microscopic tissue samples, which therefore provide a comprehensive analysis of the proteins that are associated with neuropathological features in the AD brain and proteins that are associated with selective vulnerability of specific neuronal populations. For example, we showed that amyloid plaques consistently contained hundreds of proteins in addition to $A \beta$ and that many of these were novel proteins that had not previously been associated with $\operatorname{AD}(49,50)$. Importantly, we also showed that the protein composition of amyloid plaques was significantly different in people with rapidly progressive $\mathrm{AD}$ in comparison to typical sporadic $\mathrm{AD}$, suggesting that different molecular mechanisms may underlie plaque development in different subtypes of disease. We also recently examined the proteome of NFTs and identified over 500 proteins in NFTs in addition to tau, many of which were novel (51). These examples show the power of an unbiased localized proteomics approach to efficiently identify hundreds of proteins that are associated with amyloid plaques or NFTs. These findings can be used as the basis for future targeted studies that aim to determine the mechanistic involvement of these proteins in AD.

One example protein that we discovered using proteomics and have since followed up on in a targeted study is secernin-1. Very little is known about the function of secernin-1, and no study has previously associated secernin-1 with AD. We identified secernin-1 as a novel amyloid plaque protein in our previous proteomic study of amyloid plaques (49). We have since performed a comprehensive neuropathological study of secernin-1 accumulation in early and late stage AD (52). Surprisingly, we found that secernin-1 abundantly and specifically accumulated in NFTs in AD and that its presence in amyloid plaques was limited to accumulation in the dystrophic neurites present in neuritic plaques. Co-immunoprecipitation showed that secernin-1 directly interacted with phosphorylated tau in AD brains, suggesting that it could have an important role in mediating the toxic actions of tau in AD. Intriguingly, secernin-1 colocalized with phosphorylated tau aggregates only in AD and not in other neurodegenerative diseases that also show the presence of aggregated phosphorylated tau including Pick's disease, progressive supranuclear palsy, and corticobasal degeneration. This suggests that secernin-1 could be a new potential biomarker that discriminates between AD and other tauopathies. These results show that localized proteomics studies are capable of identifying new biomarkers of disease and new potential drug targets. Secernin-1 is just one example protein from a list of many new potential candidates that we have identified in our proteomics studies that can be examined in future mechanistic studies.

A small number of other groups have also used a similar localized proteomics approach to study the proteome of neuropathological features or vulnerable cell populations/brain regions in AD. Two small studies have examined the proteome of human amyloid plaques $(53,54)$, and two small studies have examined the proteome of human NFTs $(55,56)$. Three other studies have examined the proteome of cerebral amyloid angiopathy (CAA), which is present when A $\beta$ pathologically accumulates in blood vessels (57-59). Combined, all of these studies provide preliminary data that have hinted at new proteins that are associated 
with these neuropathological features; however, the small number of cases included in these initial studies means that further studies are needed to provide a comprehensive understanding of the proteome of amyloid plaques, NFTs, and CAA. Future studies examining larger numbers of cases that are stratified by AD subtype will be very informative in helping to identify proteins that have a particular interaction with neuropathological features and to determine whether proteins associated with these neuropathological features are different between subtypes of $\mathrm{AD}$.

\section{PROTEOMICS OF SYNAPTIC FRACTIONS IN AD}

Synapse loss is an early feature of $\mathrm{AD}$ that closely correlates with cognitive impairment (60-63). Understanding the synaptic protein changes in AD could help us understand what is driving this process. Multiple studies have been completed that have analyzed the proteome of synaptosomes and post-synaptic density in control human brains, which have been nicely combined in a recent meta-analysis (64). However, a comprehensive analysis of the synaptic proteome in AD has not yet been performed. Preliminary results have been generated that analyzed the proteome of synaptosomes $(65,66)$ or post-synaptic density fractions (67). However, the small sample sizes used in these studies (between $\mathrm{n}=2$ and $\mathrm{n}=6$ ) mean that their findings are not yet definitive. Other studies have used their bulk tissue homogenate results to look specifically at synaptic protein changes $(34,68)$; however, these results could potentially miss differences in low abundance synaptic proteins. To date, all studies examining synaptic protein differences in AD have compared advanced AD and controls. Given that synaptic loss is an early feature of $\mathrm{AD}$, it would be particularly useful to determine the protein changes that contribute to synapse loss in either mild cognitive impairment or preclinical AD. Larger studies examining differences in the synaptic proteome in early AD are currently ongoing in the field, and these will likely provide a greater overview of the specific protein changes that contribute to synaptic loss in AD. Future results detailing the synaptic protein differences in $\mathrm{AD}$ will be very interesting given that it has been recently suggested that synaptic proteins in the cerebrospinal fluid may also be excellent new biomarkers for early $\operatorname{AD}(64,69)$.

\section{ANALYSIS OF THE A $\beta$ OR TAU INTERACTOME IN AD}

Another useful proteomics approach to study AD pathogenesis is using affinity purification-mass spectrometry to identify the proteins that interact with toxic $A \beta$ or tau species in $A D$. In this approach, particular species of $A \beta$ or tau are isolated from human brain samples using antibodies. Proteins that interact with $A \beta$ or tau are isolated at the same time, and mass spectrometry is used to identify these interacting proteins. This is a powerful approach because it allows the efficient and comprehensive examination of all proteins that interact with $A \beta$ or tau in an unbiased manner. It can also determine which proteins interact with particular species $A \beta$ or tau, which is important as some species are more toxic than others. 
Results from these studies have the potential to increase our understanding about how $\mathrm{A} \beta$ and tau are involved in the pathogenesis of $\mathrm{AD}$ and could lead to the discovery of new drug targets.

Despite $A \beta$ being the predominant focus of $A D$ research for decades, there is a surprisingly limited number of studies that have used affinity purification mass spectrometry to examine the $A \beta$ interactome. One possible reason for this is that it is difficult to find an appropriate antibody that specifically recognizes $A \beta$ and not its longer precursor protein (amyloid precursor protein; APP). Accordingly, a number of studies have instead examined the interactome of APP in mouse brain tissue $(70,71)$ and in cells expressing human $\operatorname{APP}(72,73)$. However, despite this limitation, there have been two recent studies that have developed alternative ways to examine the $A \beta$ interactome. The first study isolated aggregated $A \beta$ complexes from human brain samples using a non-specific $A \beta$ antibody (that also recognizes APP), but limited their downstream proteomic analysis to only those proteins present in the insoluble fraction, with the assumption that the resulting interacting proteins were limited to those present in insoluble $A \beta$-containing aggregates rather than APP (37). The second study used a more traditional approach of binding recombinant monomeric $A \beta 42$ or oligomeric $A \beta 42$ to beads that were then used to pull down interacting proteins from human brain samples (74). Combined, these studies identified over 100 proteins that interact with $A \beta$, including some proteins that preferentially interacted with oligomeric $A \beta$ in comparison to monomeric $A \beta$. However, more studies are needed in the future that compare the interactome of different $A \beta$ species (such as $A \beta 40, A \beta 42$, and pyroglutamate modified $A \beta$ ) and that determine the endogenous pathological interactions present in $\mathrm{AD}$ brain tissue, as these may be different than those present in artificial in vitro experiments.

To date, all studies examining the tau interactome have used total tau antibodies that identify proteins that interact with all tau species. Two studies have examined using human brain tissue $(37,75)$, while others have examined tau interactors in mouse brains (76-79) and in cells expressing human tau (80). These studies found that different isoforms or domains of tau regulate different protein interactions, identified the major protein families that tau preferentially binds to, and identified new potential drug targets for preventing tau toxicity. However, one limitation of these studies is that using a total tau antibody results in the identification of all proteins that interact with both physiological and pathological tau in the brain, therefore making it difficult to determine which interactions are specific to the pathological phosphorylated tau species present in AD brains. Therefore, we have recently completed the first study of the phosphorylated tau interactome in human AD brain samples (51). Our results showed that phosphorylated tau in AD brains preferentially interacted with neuronal proteins, which is consistent with the intraneuronal location of phosphorylated tau in $\mathrm{AD}$. We found that phosphorylated tau particularly interacted with proteins associated with two of the main protein degradation systems in the cell: the ubiquitin-proteasome system and the phagosome-lysosome system. The specific proteins involved suggested that phosphorylated tau may be potentially interfering with degradation of proteins by the proteasome and may contribute to lysosomal dysfunction in $\mathrm{AD}$ via interference with vacuolar ATPase proton pumps that are responsible 
for acidification of lysosomes. Impairment of both of these processes has been previously associated with AD (81-83); however, this is the first study to show that tau may be involved in this process. This is an example of the informative nature of interactome studies, showing that they can provide a complete and unbiased overview of the pathogenic brain changes that occur in AD that are directly linked to a specific toxic protein species.

Going forward, performing these studies in a systematic manner that directly compares the interactome of multiple $A \beta$ or tau species will help determine which protein interactions are particularly important for disease progression. Determining these key interactions that drive toxicity and that drive the formation of plaques or NFTs will help identify new potential drug targets for AD.

\section{CONCLUSION}

In conclusion, proteomics studies using human tissue are very useful for increasing our understanding about the pathogenesis of $\mathrm{AD}$. The combined proteomic results from studies described above provide a powerful resource for generating new hypotheses about the cause of AD. Unbiased, proteomic studies using AD brain tissue have been previously limited by concerns about cost, technical limitations, and the assumption that very large samples sizes are required to counteract the large inter-patient variability in AD. However, recent studies have shown that hundreds of significant protein differences can be detected using sample sizes as low as 5 when comparing $\mathrm{AD}$ and controls. Larger sample sizes appear to be required when comparing different stages of $\mathrm{AD}$ (e.g., preclinical $\mathrm{AD}$ vs. advanced $\mathrm{AD}$ ) or different subtypes of disease (e.g., rapidly progressive AD vs. sporadic $\mathrm{AD}$ ); however, even in these studies, 20 samples/group are sufficient to identify hundreds of protein differences between groups. These results show that discovery proteomic studies using AD brain tissue are feasible. Importantly, metaanalysis of proteomics studies using AD brain tissue shows that many altered proteins in $\mathrm{AD}$ brain tissues are consistent between studies, therefore also validating these findings.

Going forward, it will be useful to expand the scope of these previous studies. Focusing on localized proteomics changes, either in neuropathological features, vulnerable neuron populations, or synaptic fractions, has the potential to greatly increase our understanding about what protein changes drive the development of neuropathology or neurodegeneration in these particularly affected regions. Systematic examination of the proteins that interact with specific species of $A \beta$ or tau will help identify how these two proteins cause toxicity in AD. Results from localized or interactome studies have the potential to identify new drug targets or biomarkers of disease that are directly associated with $\mathrm{AD}$ neuropathology. Determining the protein changes that occur throughout the progression of $\mathrm{AD}$ is also particularly important to examine in future studies: the ideal drug targets for $\mathrm{AD}$ are pathological changes that occur in the earliest stages of disease; therefore proteomic studies that characterize protein changes in preclinical AD or mild cognitive impairment should be a priority.

Combined, proteomic studies are capable of providing a roadmap of protein changes that are associated with $\mathrm{AD}$. These studies pinpoint the protein networks 
that are most involved in disease as well as the specific proteins that are involved. Overall, these studies provide an excellent resource for future hypothesis-driven targeted studies that will hopefully help identify new biomarkers of disease and will help in the development of new drugs for AD.

Acknowledgments: This work was supported by funding from Bluesand Foundation, Australia and Dementia Australia, Australia.

Conflict of interest: The authors declare no potential conflicts of interest with respect to research, authorship, and/or publication of this chapter.

Copyright and Permission Statement: To the best of our knowledge, the materials included in this chapter do not violate copyright laws. All original sources have been appropriately acknowledged and/or referenced. Where relevant, appropriate permissions have been obtained from the original copyright holder(s).

\section{REFERENCES}

1. Livingston G, Sommerlad A, Orgeta V, Costafreda SG, Huntley J, Ames D, et al. Dementia prevention, intervention, and care. Lancet. 2017;390(10113):2673-734. http://dx.doi.org/10.1016/ S0140-6736(17)31363-6

2. DeTure MA, Dickson DW. The neuropathological diagnosis of Alzheimer's disease. Mol Neurodegener. 2019;14(1):32. http://dx.doi.org/10.1186/s13024-019-0333-5

3. Sperling R, Mormino E, Johnson K. The evolution of preclinical Alzheimer's disease: Implications for prevention trials. Neuron. 2014;84(3):608-22. http://dx.doi.org/10.1016/j.neuron.2014.10.038

4. Wisniewski T, Drummond E. Developing therapeutic vaccines against Alzheimer's disease. Expert Rev Vaccines. 2016;15(3):401-15. http://dx.doi.org/10.1586/14760584.2016.1121815

5. Herline K, Drummond E, Wisniewski T. Recent advancements toward therapeutic vaccines against Alzheimer's disease. Expert Rev Vaccines. 2018;7(8):707-21. http://dx.doi.org/10.1080/14760584.2 018.1500905

6. Cummings J. Lessons learned from Alzheimer disease: Clinical trials with negative outcomes. Clin Transl Sci. 2018;11(2):147-52. http://dx.doi.org/10.1111/cts.12491

7. Glenner GG, Wong CW. Alzheimer's disease: Initial report of the purification and characterization of a novel cerebrovascular amyloid protein. Biochem Biophys Res Commun. 1984;120(3):885-90. http:// dx.doi.org/10.1016/S0006-291X(84)80190-4

8. Masters CL, Simms G, Weinman NA, Multhaup G, McDonald BL, Beyreuther K. Amyloid plaque core protein in Alzheimer disease and down syndrome. Proc Natl Acad Sci U S A. 1985;82(12):4245-9. http://dx.doi.org/10.1073/pnas.82.12.4245

9. Grundke-Iqbal I, Iqbal K, Quinlan M, Tung YC, Zaidi MS, Wisniewski HM. Microtubule-associated protein tau. A component of Alzheimer paired helical filaments. J Biol Chem. 1986;261(13):6084-9.

10. Wisniewski T, Frangione B. Apolipoprotein E. A pathological chaperone protein in patients with cerebral and systemic amyloid. Neurosci Lett. 1992;135(2):235-8. http://dx.doi. org/10.1016/0304-3940(92)90444-C

11. Namba Y, Tomonaga M, Kawasaki H, Otomo E, Ikeda K. Apolipoprotein E immunoreactivity in cerebral amyloid deposits and neurofibrillary tangles in Alzheimer's disease and kuru plaque amyloid in Creutzfeldt-Jakob disease. Brain Res. 1991;541(1):163-6. http://dx.doi. org/10.1016/0006-8993(91)91092-F

12. Drummond E, Wisniewski T. Alzheimer's disease: Experimental models and reality. Acta Neuropathol. 2017;133(2):155-75. http://dx.doi.org/10.1007/s00401-016-1662-x 
13. Kunkle BW, Grenier-Boley B, Sims R, Bis JC, Damotte V, Naj AC, et al. Genetic meta-analysis of diagnosed Alzheimer's disease identifies new risk loci and implicates Abeta, tau, immunity and lipid processing. Nat Genet. 2019;51(3):414-30. http://dx.doi.org/10.1038/s41588-019-0358-2

14. Jansen IE, Savage JE, Watanabe K, Bryois J, Williams DM, Steinberg S, et al. Genome-wide metaanalysis identifies new loci and functional pathways influencing Alzheimer's disease risk. Nature Genet. 2019;51(3):404-13. http://dx.doi.org/10.1038/s41588-018-0311-9

15. De Jager PL, Srivastava G, Lunnon K, Burgess J, Schalkwyk LC, Yu L, et al. Alzheimer's disease: Early alterations in brain DNA methylation at ANK1, BIN1, RHBDF2 and other loci. Nat Neurosci. 2014;17(9):1156-63. http://dx.doi.org/10.1038/nn.3786

16. Lunnon K, Smith R, Hannon E, De Jager PL, Srivastava G, Volta M, et al. Methylomic profiling implicates cortical deregulation of ANKl in Alzheimer's disease. Nat Neurosci. 2014;17(9):1164-70. http://dx.doi.org/10.1038/nn.3782

17. Seyfried NT, Dammer EB, Swarup V, Nandakumar D, Duong DM, Yin L, et al. A multi-network approach identifies protein-specific co-expression in asymptomatic and symptomatic Alzheimer's disease. Cell Syst. 2017;4(1):60-72.e4. http://dx.doi.org/10.1016/j.cels.2016.11.006

18. Drummond E, Goni F, Liu S, Prelli F, Scholtzova H, Wisniewski T. Potential novel approaches to understand the pathogenesis and treat Alzheimer's disease. J Alzheimer's Dis JAD. 2018;64(Suppl 1): S299-312. http://dx.doi.org/10.3233/JAD-179909

19. Wisniewski T, Drummond E. Future Horizons in Alzheimer's Disease Research. In: David B. Teplow, editor. Molecular biology of neurodegenerative diseases: Visions for the future. Prog Mol Biol Transl Sci. Elsevier; 2019;168:223-241. http://dx.doi.org/10.1016/bs.pmbts.2019.08.001.

20. Castano EM, Maarouf CL, Wu T, Leal MC, Whiteside CM, Lue LF, et al. Alzheimer disease periventricular white matter lesions exhibit specific proteomic profile alterations. Neurochem Int. 2013;62(2):145-56. http://dx.doi.org/10.1016/j.neuint.2012.12.001

21. Gozal YM, Duong DM, Gearing M, Cheng D, Hanfelt JJ, Funderburk C, et al. Proteomics analysis reveals novel components in the detergent-insoluble subproteome in Alzheimer's disease. J Proteome Res. 2009;8(11):5069-79. http://dx.doi.org/10.1021/pr900474t

22. Musunuri S, Wetterhall M, Ingelsson M, Lannfelt L, Artemenko K, Bergquist J, et al. Quantification of the brain proteome in Alzheimer's disease using multiplexed mass spectrometry. J Proteome Res. 2014;13(4):2056-68. http://dx.doi.org/10.1021/pr401202d

23. Musunuri S, Kultima K, Richard BC, Ingelsson M, Lannfelt L, Bergquist J, et al. Micellar extraction possesses a new advantage for the analysis of Alzheimer's disease brain proteome. Anal Bioanal Chem. 2015;407(4):1041-57. http://dx.doi.org/10.1007/s00216-014-8320-8

24. Donovan LE, Higginbotham L, Dammer EB, Gearing M, Rees HD, Xia Q, et al. Analysis of a membrane-enriched proteome from postmortem human brain tissue in Alzheimer's disease. Proteomics Clin Appl. 2012;6(3-4):201-11. http://dx.doi.org/10.1002/prca.201100068

25. Bai B, Hales CM, Chen PC, Gozal Y, Dammer EB, Fritz JJ, et al. Ul small nuclear ribonucleoprotein complex and RNA splicing alterations in Alzheimer's disease. Proc Natl Acad Sci U S A. 2013;110(41):16562-7. http://dx.doi.org/10.1073/pnas.1310249110

26. Begcevic I, Kosanam H, Martinez-Morillo E, Dimitromanolakis A, Diamandis P, Kuzmanov U, et al. Semiquantitative proteomic analysis of human hippocampal tissues from Alzheimer's disease and agematched control brains. Clin Proteomics. 2013;10(1):5. http://dx.doi.org/10.1186/1559-0275-10-5

27. Andreev VP, Petyuk VA, Brewer HM, Karpievitch YV, Xie F, Clarke J, et al. Label-free quantitative LC-MS proteomics of Alzheimer's disease and normally aged human brains. J Proteome Res. 2012;11(6):3053-67. http://dx.doi.org/10.1021/pr3001546

28. Hondius DC, van Nierop P, Li KW, Hoozemans JJ, van der Schors RC, van Haastert ES, et al. Profiling the human hippocampal proteome at all pathologic stages of Alzheimer's disease. Alzheimers Dementia. 2016;12(6):654-68. http://dx.doi.org/10.1016/j.jalz.2015.11.002

29. Ho Kim J, Franck J, Kang T, Heinsen H, Ravid R, Ferrer I, et al. Proteome-wide characterization of signalling interactions in the hippocampal CA4/DG subfield of patients with Alzheimer's disease. Sci Rep. 2015;5:11138. http://dx.doi.org/10.1038/srepl1138

30. Hales CM, Dammer EB, Deng Q, Duong DM, Gearing M, Troncoso JC, et al. Changes in the detergentinsoluble brain proteome linked to amyloid and tau in Alzheimer's disease progression. Proteomics. 2016;16(23):3042-53. http://dx.doi.org/10.1002/pmic.201600057 
31. Johnson ECB, Dammer EB, Duong DM, Yin L, Thambisetty M, Troncoso JC, et al. Deep proteomic network analysis of Alzheimer's disease brain reveals alterations in RNA binding proteins and RNA splicing associated with disease. Mol Neurodegener. 2018;13(1):52. http://dx.doi.org/10.1186/ s13024-018-0282-4

32. Zhang Q, Ma C, Gearing M, Wang PG, Chin LS, Li L. Integrated proteomics and network analysis identifies protein hubs and network alterations in Alzheimer's disease. Acta Neuropathol Commun. 2018;6(1):19. http://dx.doi.org/10.1186/s40478-018-0524-2

33. Dai J, Johnson ECB, Dammer EB, Duong DM, Gearing M, Lah JJ, et al. Effects of APOE genotype on brain proteomic network and cell type changes in Alzheimer's disease. Front Mol Neurosci. 2018;11:454. http://dx.doi.org/10.3389/fnmol.2018.00454

34. Bereczki E, Branca RM, Francis PT, Pereira JB, Baek JH, Hortobagyi T, et al. Synaptic markers of cognitive decline in neurodegenerative diseases: A proteomic approach. Brain. 2018;141(2):582-95. http:// dx.doi.org/10.1093/brain/awx352

35. Strittmatter WJ, Saunders AM, Schmechel D, Pericak-Vance M, Enghild J, Salvesen GS, et al. Apolipoprotein E: High-avidity binding to beta-amyloid and increased frequency of type 4 allele in late-onset familial Alzheimer disease. Proc Natl Acad Sci U S A. 1993;90(5):1977-81. http://dx.doi. org/10.1073/pnas.90.5.1977

36. Corder EH, Saunders AM, Risch NJ, Strittmatter WJ, Schmechel DE, Gaskell PC Jr., et al. Protective effect of apolipoprotein E type 2 allele for late onset Alzheimer disease. Nat Genet. 1994;7(2):180-4. http://dx.doi.org/10.1038/ng0694-180

37. Ayyadevara S, Balasubramaniam M, Parcon PA, Barger SW, Griffin WS, Alla R, et al. Proteins that mediate protein aggregation and cytotoxicity distinguish Alzheimer's hippocampus from normal controls. Aging Cell. 2016;15(5):924-39. http://dx.doi.org/10.1111/acel.12501

38. Abreha MH, Dammer EB, Ping L, Zhang T, Duong DM, Gearing M, et al. Quantitative analysis of the brain ubiquitylome in Alzheimer's disease. Proteomics. 2018;18(20):e1800108. http://dx.doi. org/10.1002/pmic.201800108

39. Dammer EB, Lee AK, Duong DM, Gearing M, Lah JJ, Levey AI, et al. Quantitative phosphoproteomics of Alzheimer's disease reveals cross-talk between kinases and small heat shock proteins. Proteomics. 2015;15(2-3):508-19. http://dx.doi.org/10.1002/pmic.201400189

40. Mrdjen D, Fox EJ, Bukhari SA, Montine KS, Bendall SC, Montine TJ. The basis of cellular and regional vulnerability in Alzheimer's disease. Acta Neuropathol. 2019; 138(5):729-749. http://dx.doi. org/10.1007/s00401-019-02054-4

41. Fu H, Hardy J, Duff KE. Selective vulnerability in neurodegenerative diseases. Nature Neurosci. 2018;21(10):1350-8. http://dx.doi.org/10.1038/s41593-018-0221-2

42. Mattsson N, Schott JM, Hardy J, Turner MR, Zetterberg H. Selective vulnerability in neurodegeneration: Insights from clinical variants of Alzheimer's disease. J Neurol Neurosurg Psychiatry. 2016;87(9):1000-4. http://dx.doi.org/10.1136/jnnp-2015-311321

43. Grothe MJ, Sepulcre J, Gonzalez-Escamilla G, Jelistratova I, Scholl M, Hansson O, et al. Molecular properties underlying regional vulnerability to Alzheimer's disease pathology. Brain. 2018;141(9): 2755-71. http://dx.doi.org/10.1093/brain/awy189

44. Xu J, Patassini S, Rustogi N, Riba-Garcia I, Hale BD, Phillips AM, et al. Regional protein expression in human Alzheimer's brain correlates with disease severity. Commun Biol. 2019;2:43. http://dx.doi. org/10.1038/s42003-018-0254-9

45. Mendonca CF, Kuras M, Nogueira FCS, Pla I, Hortobagyi T, Csiba L, et al. Proteomic signatures of brain regions affected by tau pathology in early and late stages of Alzheimer's disease. Neurobiol Dis. 2019;130:104509. http://dx.doi.org/10.1016/j.nbd.2019.104509

46. Drummond E, Nayak S, Pires G, Ueberheide B, Wisniewski T. Isolation of amyloid plaques and neurofibrillary tangles from archived Alzheimer's disease tissue using laser-capture microdissection for downstream proteomics. Methods Mol Biol. 2018;1723:319-34. http://dx.doi. org/10.1007/978-1-4939-7558-7_18

47. Drummond E, Nayak S, Ueberheide B, Wisniewski T. Localized proteomics of individual neurons isolated from formalin-fixed, paraffin embedded tissue sections using laser capture microdissection. In: Martinez ES, Fernández J, editors. Current proteomic approaches applied to brain function. New York: Humana Press; 2017. p. 289-301. 
48. Drummond ES, Nayak S, Ueberheide B, Wisniewski T. Proteomic analysis of neurons microdissected from formalin-fixed, paraffin-embedded Alzheimer's disease brain tissue. Sci Rep. 2015;5:15456. http://dx.doi.org/10.1038/srep15456

49. Drummond E, Nayak S, Faustin A, Pires G, Hickman RA, Askenazi M, et al. Proteomic differences in amyloid plaques in rapidly progressive and sporadic Alzheimer's disease. Acta Neuropathol. 2017;133(6):933-54. http://dx.doi.org/10.1007/s00401-017-1691-0

50. DrummondE, Wisniewski T. The use of localized proteomics to identify the drivers of Alzheimer's disease pathogenesis. Neural Regen Res. 2017;12(6):912-13. http://dx.doi.org/10.4103/1673-5374.208570

51. Drummond E, Pires G, MacMurray, C, Askenazi M, Nayak S, Bourdon M, Ueberheide B, Wisniewski T. Phosphorylated tau interactome in the human Alzheimer's disease brain. Alzheimer's and Dementia. 2019;15(7):1517. https://doi.org/10.1016/j.jalz.2019.08.077

52. Pires G, McElligott S, Drusinsky S, Halliday G, Potier MC, Wisniewski T, Drummond E. Secernin-1 is a novel phosphorylated tau binding protein that accumulates in Alzheimer's disease and not in other tauopathies. Acta Neuropathol Commun. 2019. In Press. http://dx.doi.org/10.1186/s40478-019-0848-6

53. Xiong F, Ge W, Ma C. Quantitative proteomics reveals distinct composition of amyloid plaques in Alzheimer's disease. Alzheimers Dementia. 2019;15(3):429-40. http://dx.doi.org/10.1016/j. jalz.2018.10.006

54. Liao L, Cheng D, Wang J, Duong DM, Losik TG, Gearing M, et al. Proteomic characterization of postmortem amyloid plaques isolated by laser capture microdissection. J Biol Chem. 2004;279(35): 37061-8. http://dx.doi.org/10.1074/jbc.M403672200

55. Wang Q, Woltjer RL, Cimino PJ, Pan C, Montine KS, Zhang J, et al. Proteomic analysis of neurofibrillary tangles in Alzheimer disease identifies GAPDH as a detergent-insoluble paired helical filament tau binding protein. FASEB J. 2005;19(7):869-71. http://dx.doi.org/10.1096/fj.04-3210fje

56. Minjarez B, Valero Rustarazo ML, Sanchez del Pino MM, Gonzalez-Robles A, Sosa-Melgarejo JA, LunaMunoz J, et al. Identification of polypeptides in neurofibrillary tangles and total homogenates of brains with Alzheimer's disease by tandem mass spectrometry. J Alzheimers Dis JAD. 2013;34(1): 239-62. http://dx.doi.org/10.3233/JAD-121480

57. Manousopoulou A, Gatherer M, Smith C, Nicoll JAR, Woelk CH, Johnson M, et al. Systems proteomic analysis reveals that clusterin and tissue inhibitor of metalloproteinases 3 increase in leptomeningeal arteries affected by cerebral amyloid angiopathy. Neuropathol Appl Neurobiol. 2017;43(6):492-504. http://dx.doi.org/10.1111/nan.12342

58. Inoue Y, Ueda M, Tasaki M, Takeshima A, Nagatoshi A, Masuda T, et al. Sushi repeat-containing protein 1: A novel disease-associated molecule in cerebral amyloid angiopathy. Acta Neuropathol. 2017;134(4):605-17. http://dx.doi.org/10.1007/s00401-017-1720-z

59. Hondius DC, Eigenhuis KN, Morrema THJ, van der Schors RC, van Nierop P, Bugiani M, et al. Proteomics analysis identifies new markers associated with capillary cerebral amyloid angiopathy in Alzheimer's disease. Acta Neuropathol Commun. 2018;6(1):46. http://dx.doi.org/10.1186/ s40478-018-0540-2

60. Selkoe DJ. Alzheimer's disease is a synaptic failure. Science. 2002;298(5594):789-91. http://dx.doi. org/10.1126/science. 1074069

61. Scheff SW, Price DA, Schmitt FA, DeKosky ST, Mufson EJ. Synaptic alterations in CAl in mild Alzheimer disease and mild cognitive impairment. Neurology. 2007;68(18):1501-8. http://dx.doi. org/10.1212/01.wnl.0000260698.46517.8f

62. Terry RD, Masliah E, Salmon DP, Butters N, DeTeresa R, Hill R, et al. Physical basis of cognitive alterations in Alzheimer's disease: Synapse loss is the major correlate of cognitive impairment. Ann Neurol. 1991;30(4):572-80. http://dx.doi.org/10.1002/ana.410300410

63. DeKosky ST, Scheff SW. Synapse loss in frontal cortex biopsies in Alzheimer's disease: Correlation with cognitive severity. Ann Neurol. 1990;27(5):457-64. http://dx.doi.org/10.1002/ana.410270502

64. Lleo A, Nunez-Llaves R, Alcolea D, Chiva C, Balateu-Panos D, Colom-Cadena M, et al. Changes in synaptic proteins precede neurodegeneration markers in preclinical Alzheimer's disease cerebrospinal fluid. Mol Cell Proteomics. 2019;18(3):546-60. http://dx.doi.org/10.1074/mcp.RA118.001290

65. Chang RY, Etheridge N, Nouwens AS, Dodd PR. SWATH analysis of the synaptic proteome in Alzheimer's disease. Neurochem Int. 2015;87:1-12. http://dx.doi.org/10.1016/j.neuint.2015.04.004

66. Chang RY, Nouwens AS, Dodd PR, Etheridge N. The synaptic proteome in Alzheimer's disease. Alzheimers Dementia. 2013;9(5):499-511. http://dx.doi.org/10.1016/j.jalz.2012.04.009 
67. Zhou J, Jones DR, Duong DM, Levey AI, Lah JJ, Peng J. Proteomic analysis of postsynaptic density in Alzheimer's disease. Clin Chim Acta. 2013;420:62-8. http://dx.doi.org/10.1016/j.cca.2013.03.016

68. Sweet RA, MacDonald ML, Kirkwood CM, Ding Y, Schempf T, Jones-Laughner J, et al. Apolipoprotein E*4 (APOE*4) genotype is associated with altered levels of glutamate signaling proteins and synaptic coexpression networks in the prefrontal cortex in mild to moderate Alzheimer disease. Mol Cell Proteomics. 2016;15(7):2252-62. http://dx.doi.org/10.1074/mcp.M115.056580

69. Duits FH, Brinkmalm G, Teunissen CE, Brinkmalm A, Scheltens P, Van der Flier WM, et al. Synaptic proteins in CSF as potential novel biomarkers for prognosis in prodromal Alzheimer's disease. Alzheimers Res Ther. 2018;10(1):5. http://dx.doi.org/10.1186/s13195-017-0335-x

70. Bai Y, Markham K, Chen F, Weerasekera R, Watts J, Horne P, et al. The in vivo brain interactome of the amyloid precursor protein. Mol Cell Proteomics. 2008;7(1):15-34. http://dx.doi.org/10.1074/mcp. M700077-MCP200

71. Kohli BM, Pflieger D, Mueller LN, Carbonetti G, Aebersold R, Nitsch RM, et al. Interactome of the amyloid precursor protein APP in brain reveals a protein network involved in synaptic vesicle turnover and a close association with synaptotagmin-1. J Proteome Res. 2012;11(8):4075-90. http:// dx.doi.org/10.1021/pr300123g

72. Hosp F, Vossfeldt H, Heinig M, Vasiljevic D, Arumughan A, Wyler E, et al. Quantitative interaction proteomics of neurodegenerative disease proteins. Cell Rep. 2015;11(7):1134-46. http://dx.doi. org/10.1016/j.celrep.2015.04.030

73. Andrew RJ, Fisher K, Heesom KJ, Kellett KAB, Hooper NM. Quantitative interaction proteomics reveals differences in the interactomes of amyloid precursor protein isoforms. J Neurochem. 2019;149(3):399-412. http://dx.doi.org/10.1111/jnc.14666

74. Wang H, Muiznieks LD, Ghosh P, Williams D, Solarski M, Fang A, et al. Somatostatin binds to the human amyloid beta peptide and favors the formation of distinct oligomers. eLife. 2017;6:pii: e28401. http://dx.doi.org/10.7554/eLife.28401

75. Meier S, Bell M, Lyons DN, Ingram A, Chen J, Gensel JC, et al. Identification of novel tau interactions with endoplasmic reticulum proteins in Alzheimer's disease brain. J Alzheimers Dis JAD. 2015;48(3):687-702. http://dx.doi.org/10.3233/JAD-150298

76. Liu C, Song X, Nisbet R, Gotz J. Co-immunoprecipitation with tau isoform-specific antibodies reveals distinct protein interactions and highlights a putative role for $2 \mathrm{~N}$ tau in disease. J Biol Chem. 2016;291(15):8173-88. http://dx.doi.org/10.1074/jbc.M115.641902

77. Maziuk BF, Apicco DJ, Cruz AL, Jiang L, Ash PEA, da Rocha EL, et al. RNA binding proteins colocalize with small tau inclusions in tauopathy. Acta Neuropathol Commun. 2018;6(1):71. http:// dx.doi.org/10.1186/s40478-018-0574-5

78. Wang P, Joberty G, Buist A, Vanoosthuyse A, Stancu IC, Vasconcelos B, et al. Tau interactome mapping based identification of Otubl as Tau deubiquitinase involved in accumulation of pathological Tau forms in vitro and in vivo. Acta Neuropathol. 2017;133(5):731-49. http://dx.doi.org/10.1007/ s00401-016-1663-9

79. Stefanoska K, Volkerling A, Bertz J, Poljak A, Ke YD, Ittner LM, et al. An N-terminal motif unique to primate tau enables differential protein-protein interactions. J Biol Chem. 2018;293(10):3710-19. http://dx.doi.org/10.1074/jbc.RAl18.001784

80. Gunawardana CG, Mehrabian M, Wang X, Mueller I, Lubambo IB, Jonkman JE, et al. The human tau interactome: Binding to the ribonucleoproteome, and impaired binding of the proline-toleucine mutant at position 301 (P301L) to chaperones and the proteasome. Mol Cell Proteomics. 2015;14(11):3000-14. http://dx.doi.org/10.1074/mcp.M115.050724

81. Keck S, Nitsch R, Grune T, Ullrich O. Proteasome inhibition by paired helical filament-tau in brains of patients with Alzheimer's disease. J Neurochem. 2003;85(1):115-22. http://dx.doi. org/10.1046/j.1471-4159.2003.01642.x

82. Keller JN, Hanni KB, Markesbery WR. Impaired proteasome function in Alzheimer's disease. J Neurochem. 2000;75(1):436-9. http://dx.doi.org/10.1046/j.1471-4159.2000.0750436.x

83. Colacurcio DJ, Nixon RA. Disorders of lysosomal acidification-the emerging role of v-ATPase in aging and neurodegenerative disease. Ageing Res Rev. 2016;32:75-88. http://dx.doi.org/10.1016/j. arr.2016.05.004 